This is an Accepted Manuscript of an article published by Taylor \& Francis in "Journal of Natural Fibers" on $10^{\text {th }}$ August 2020, available online:

https://www.tandfonline.com/doi/abs/10.1080/15440478.2020.17988 41 


\section{Human hair biogenic fiber as a biosorbent of multiple heavy metals from aqueous solutions}

Abstract: Human hair natural fiber is mainly considered a waste in our society and its disposal can cause a major environmental impact. Hence, its valorization as a biosorbent of pollutants such as heavy metals is an interesting route to explore since it can reduce the amount of waste and at the same time contributes to the circular economy strategy. In this work, the ability of two kind of human hairs, used as biosorbents to remove $\mathrm{Cr}(\mathrm{III}), \mathrm{Ni}(\mathrm{II}), \mathrm{Co}(\mathrm{II}), \mathrm{Mn}(\mathrm{II}), \mathrm{Cu}(\mathrm{II}), \mathrm{Zn}(\mathrm{II}), \mathrm{Cd}(\mathrm{II})$ and $\mathrm{Pb}(\mathrm{II})$ ions from multiple-metal aqueous solutions, were examined and compared under different operating conditions. The influence of the time, $\mathrm{pH}$ and initial metal concentration on the metal uptake were studied. The biosorption kinetics and isotherm were also modeled observing that pseudo-second order kinetic model and Langmuir model fitted successfully experimental data. Moreover, biosorption process did not significantly modify the morphology and the chemical structure of the hair samples, which was proved by SEM and FT-IR studies. These kinetic results underline the satisfactory capacity of human hair for the biosorption of $\mathrm{Pb}$ (II), $\mathrm{Cu}$ (II) and $\mathrm{Cr}$ (II) (values up to $95 \%$ ), pointing up the high efficacy of human hair for the removal of heavy metal ions from aqueous media.

Keywords: Hair; Biofibre; Metals; Biosorption; Kinetics; Isotherms

\section{Introduction}

Intensifying environment pollution and deteriorating of ecosystems anthropologically, caused by mainly industrial activities, have seriously threatened human existence and development (Wang et al., 2020). Compared with other pollutants, such as dye (Lazaridis et al., 2007), phenols (Sas et al. 2020), inorganic anions, and pesticides (which are toxic to many living lifeforms and organisms), heavy metal ions are extremely harmful to human, animals, and plants because of their toxicity, accumulation, no biodegradable nature and causing various diseases and disorders (Patnaik et al., 2004). Different methodologies, including precipitation, flotation, ion exchange, membrane-related processes, electrochemical techniques and activated 
carbon adsorption, have been actually established for the removal of heavy metal ions from aqueous effluents (Carolin et al., 2017). Some of these methods are often too expensive to be applied on a large scale or cost prohibitive due to having inadequate efficacy at low metal concentrations (Low, Lee and Liew 2000). So, considering the importance of the removal of heavy metal ions from aqueous effluents, it is necessary to put emphasis on searching new, clean and cheap technologies that can improve upon these methods (Qin et al., 2020). Biosorption techniques have attracted more attention in recent years, not only due to its particular use for the removal of trace levels of contaminants from industrial effluents, but also due to economic reasons (Tran et al., 2019). Biosorption can be defined as the ability of biological materials to accumulate compounds such as heavy metal ions, from effluents through metabolically mediated or physical-chemical pathways of uptake (Beni and Esmaeili, 2020). Although biosorption process is complicated, it can be simply approached as a combination of physical and chemical sorption mechanism (Davis, Volesky and Mucci, 2003) based on the strong chemical interactions between heavy metal ions and some functional groups which can be present on the biomass surface, such as carboxyl, hydroxyl, phosphate, sulfate, and amino groups that act as binders for these ions (Ahalya, Ramachandra and Kanamadi, 2003). Actually, many low-cost and commercially available biomass such as cork waste (López-Mesas et al., 2011), moss peat (Seki et al., 2006), tree leaves (Kaakani, Mortula and Abouleish, 2017), wheat (Gorgievski et al., 2013), rice (Amer, El-Gendy and El-Haggar, 2017) and sugar beet pulp (Castro et al., 2017) have been used to remove heavy metal ions. Although many kinds of biomass have been reported to remove heavy metal ions, these studies just focused on single or few metal ions mixture system (less than 3 species). Considering that multiple metal ions mixture exists abundantly in natural and aqueous effluents, understanding how biomass removes metal ions in their multiple ion mixtures is interesting and useful for practical applications and for the development of the corresponding treatment of such contaminated sites by using these biomass systems (Zhao et al., 2019).

Among many other biosorbent materials, keratinous materials contain intricate networks of stable and 
water-insoluble fibers with high surface areas and are biogenic abundant bioresources (Kar and Misra, 2004)

(Saha et al., 2019). Particularly, keratinous-composed human hair is considered an ubiquitous waste and its accumulation can cause environmental problems. Hence, the search for alternatives that take advantages of this waste as a new raw material is interesting thus contributing to the idea of circular economy (Gupta, 2014). "For instance, human hair has been proposed for being used for several applications such as: i) fashion and cosmetic industry (test Material for hair care products, cosmetic brushes), ii) fertilizer because it is predominantly made up of nitrogen-containing proteins (Zheljazko V. D. et al., 2008), iii) reinforcement of construction materials due to high tensile strength and thermal insulation capacity (Butt, W.A., Mir, B.A. and Jha, J.N., 2016), iv) oil spill remediation (Ukotije-Ikwut P.R. et al., 2016) and v) pharmaceuticals and biomedical applications since human hair is composed of 20 essential amino acids (Lee, H. et al., 2014)". Moreover, the presence of carboxyl, amido and disulfide groups in human hair postulate this waste as a good biosorbent of several chemicals such as heavy metals although it has been rarely studied for this application (Zhang et al., 2019) (Krishnan S.S, Cancilla A. and Jervis R.E, 1988) (Tan T.C., Chia C.K. and Teo C.K., 1985). Based on these favorable aforementioned properties, the use of human hair as biosorbent could be potentially a low cost alternative for removing metal mixtures from aqueous effluents. So, human hair is presented in this work as a biosorbent for the elimination of heavy metal ions such as $\mathrm{Cr}(\mathrm{III}), \mathrm{Mn}(\mathrm{II}), \mathrm{Co}(\mathrm{II})$, $\mathrm{Ni}(\mathrm{II}), \mathrm{Cu}(\mathrm{II}), \mathrm{Zn}(\mathrm{II}), \mathrm{Cd}(\mathrm{II})$ and $\mathrm{Pb}(\mathrm{II})$ from multiple aqueous solutions and under different operating conditions. Considering the important role of the chemical structure and the surface properties of human hair in the metal biosorption process, two different kinds of hair were employed and their biosorption effectiveness of heavy metal ions was compared. One sample is untreated human hair (H1), and the other is periodically bleached and dyed hair, which is considered as the treated hair $(\mathbf{H 2})$. Operational parameters affecting the biosorption process such as the contact time, the $\mathrm{pH}$ of the aqueous metal media, and the initial heavy metal concentration were studied in both cases. Biosorption kinetics and equilibrium isotherms were modelled. 
Based on the afore mentioned considerations, the aim of this work was to study the effectiveness of human hair as a biosorbent for the removal of heavy metal ions in multiple-metal aqueous solutions and the effect of the main operational parameters on the biosorption step.

\section{Experimental}

\subsection{Materials and methods}

Human hair was collected from local barbershops. The untreated hair was from a 27-year old human (H1), and the treated (bleached and dyed) hair was from a 45-year old human (H2). The collected hair was washed with commercial detergent, rinsed several times with deionized water (purified with a milli-Q Gradient system from Millipore Corporation ) and then left to dry at room temperature $\left(22 \pm 1^{\circ} \mathrm{C}\right)$. The hair was cut to an approximate length of 1-2 mm by using scissors. Particle size has been reduced and controlled (restricted to 1-2 $\mathrm{mm}$ ) since, as it has been reported previously, the biosorption increase as the range of particle size becomes thinner since smaller particles give large surface areas (Shim Y. S. et al., 2003 and Amuda O.S. et al., 2007). All chemicals used were of analytical grade. Stock solutions of separate heavy metal ions, such as $\mathrm{Cr}(\mathrm{III}), \mathrm{Mn}(\mathrm{II}), \mathrm{Co}(\mathrm{II}), \mathrm{Ni}(\mathrm{II}), \mathrm{Cu}(\mathrm{II}), \mathrm{Zn}(\mathrm{II}), \mathrm{Cd}(\mathrm{II})$ and $\mathrm{Pb}(\mathrm{II})$ were prepared by dissolving their nitric salts (>99\%, all from Panreac, Spain) in deionized water. A 1000 ppm stock solution of each metal ion was first prepared. The initial multiple heavy metal aqueous solution was properly

prepared by including eight metals at the concentration level required for each experiment, so, at the corresponding dilution level. Sodium hydroxide ( $>98 \%$, from Panreac, Spain) and nitric acid ( $>70 \%$, from JT-Baker, Spain) were alternatively used for the $\mathrm{pH}$ adjustment of the initial aqueous solution prior commencing the biosorption experiments. In all the experiments, the initial $\mathrm{pH}$ was measured, and usually the final pH was also checked, using an Omega $300 \mathrm{pH}$ meter (Crison instruments, S.A., Spain).

\subsection{Biosorption procedure}

The biosorption step was carried out under batch operation mode at a constant temperature of $22 \pm 1{ }^{\circ} \mathrm{C}$. In all sets of experiments, $0.100 \mathrm{~g}$ of human hair was accurately weighted in $50 \mathrm{~mL}$ plastic extraction tubes, 
and $10 \mathrm{~mL}$ of the multiple heavy metal aqueous solution was added. The system was properly shaken on a rotary mixer (CE 2000 ABT-4, SBS Instruments SA, Barcelona, Spain) at $25 \mathrm{rpm}$, during the desired time. After that, solid was separated from the liquid by subsequent decantation and the liquid was filtered through $0.22 \mu \mathrm{m}$ syringe filter (CN-CA Syringe Filter, HEAION, USA). Finally, to completely separate the biomaterial, a filtration step is added. Later, the metal concentration in the remaining aqueous solutions was determined by an inductively coupled plasma optical emission spectrophotometer with mass detector, ICP-MS (XSERIES 2 ICP-MS, Thermo Scientific, USA).

The uptake of each metal ion by each sample of human hair was calculated using equation 1 :

$\%$ biosorption $=\frac{C_{i}-C_{f}}{C_{i}} \times 100$

where $C_{i}$ and $C_{f}$ are the initial and the final concentration at an specific time of heavy metal in the aqueous phase solution, respectively (in mmol/L).

The exchange capacity $\left(q_{t}\right)$ is the concentration of biosorbed metal ion per unit of mass of biosorbent (in $\mathrm{mmol} / \mathrm{g}$ ) at time $t$, which was calculated using the equation 2 :

$q_{t}(\mathrm{mmol} / \mathrm{g})=\frac{\left(C_{i}-C_{f}\right) \times V}{W}$

where $V$ is the total volume of the solution (in L), $W$ is the amount of biosorbent (in $\mathrm{g}$ ), $C_{i}$ and $C_{f}$ are the initial and the final concentrations of heavy metal (each given in units of mmol/L), respectively.

The amount of metal sorbed $\left(q_{e}\right)$, is the concentration of biosorbed metal ion per unit of mass of biosorbent (in $\mathrm{mmol} / \mathrm{g}$ ) at the equilibrium, which was obtained as follows (equation 3):

$q_{e}(\mathrm{mmol} / \mathrm{g})=\frac{\left(C_{i}-C_{e}\right) \times V}{W}$

where $V$ is the total volume of the solution (in L), $W$ is the amount of biosorbent (in $\mathrm{g}$ ), $C_{i}$ and $C_{e}$ are the initial and equilibrium concentrations of heavy metal in the aqueous solution (each given in units of $\mathrm{mmol} / \mathrm{L})$, respectively.

For the kinetics studies, the initial metal ion concentration was set at $0.18 \mathrm{mmol} / \mathrm{L}$ (for each of the 
heavy metal ion under study) (López-Mesas et al., 2011). The initial pH of the multiple heavy metal aqueous solution (also at $0.18 \mathrm{mmol} / \mathrm{L}$ for each heavy metal ion) was varied within the range 1.0-6.0 when determining the influence of this parameter in the biosorption process (higher $\mathrm{pH}$ values are not evaluated to avoid metal hydroxides precipitation). The initial heavy metal concentration was ranged from $0.5 \times 10^{-3}$ to 0.5 $\mathrm{mmol} / \mathrm{L}$ for the removal of heavy metals from multiple-metal system when determining the effect of initial concentration. Finally, biosorption isotherm of $\mathrm{Pb}(\mathrm{II})$ in single-metal system into human hairs was studied at different initial concentration levels $\left(0.5 \times 10^{-3}\right.$ to $\left.4 \mathrm{mmol} / \mathrm{L} \mathrm{mmol} / \mathrm{L}\right)$. The $\mathrm{pH}$ was adjusted at 4.0 , unless otherwise stated.

Each test was carried out in duplicate and the average values are shown in the corresponding figures (experimental errors found were less than $2 \%$ and $5.0 \times 10^{-5} \mathrm{mmol} / \mathrm{g}$ in the biosorption percentage and the biosorption capacity, respectively).

\subsection{Hair characterization}

FTIR and SEM analysis were employed to determine whether the heavy metal biosorption process has some influence in the chemical or on the morphological structure of the hair. To do so, small portions prepared from $\mathbf{H 1}$ and $\mathbf{H 2}$ samples, before and after the biosorption process were checked. For the FTIR analysis, a Bruker Fourier Transform Infrared Spectrometer (FTIR) (Tensor 27, Bruker, Germany) was used. In this case, samples less than $1 \mathrm{mg}$ were used. The spectrum was recorded in the range of $600-4000 \mathrm{~cm}^{-1}$ with 16 scans and a resolution of $4 \mathrm{~cm}^{-1}$. SEM images were obtained by using a scanning electronic microscope (ZEISS EVO MA 10, Oberkochen, Germany) at the UAB Microscopy Service. The sample used sputter-coating arrangement.

\section{Results and discussion}

\subsection{Influence of the $\mathrm{pH}$ on the heavy metal uptake}

The $\mathrm{pH}$ has both influences on the metal aqueous speciation and on the chemical functional groups speciation on the active sites of the hair surface (Liu et al., 2007). The effect of the initial $\mathrm{pH}$ on the 
biosorption capacity was studied in the range of $\mathrm{pH} 1.0$ to 6.0 at an initial concentration of metals in solution of $0.18 \mathrm{mmol} / \mathrm{L}$. As showed in Figure 1, in both hair systems the metal uptake was strongly dependent on the $\mathrm{pH}$ value of the aqueous solutions. At an initial $\mathrm{pH}$ value lower than 3.0, little biosorption occurred for H1 and H2, and especially at $\mathrm{pH} 1.0$ almost no biosorption was observed. A sharply increase in the biosorption capacity took place in the $\mathrm{pH}$ range between 3.0 and 5.0 for all heavy metal ions. Above $\mathrm{pH} 5.0$, biosorption of all metal ions were found to be relatively constant. The low biosorption capacity at $\mathrm{pH}$ values below than 3.0 is attributed to the high concentration of $\mathrm{H}^{+}$ions. In this situation, the concentration of $\mathrm{H}^{+}$ ions far exceeds the metal ions concentration in the solution and hence $\mathrm{H}^{+}$compete with them for reaching the hair surface binding sites (Olgun and Atar, 2012). So, the reduction of protons can efficiently decrease the competition between metal ions and $\mathrm{H}^{+}$ions on the biosorbent surface and increase the biosorption metal capacity of the hair.

\section{(Insert Figure 1 here)}

Although biosorption process for $\mathbf{H 1}$ and $\mathbf{H 2}$ show similar trend with the $\mathrm{pH}$, there are some clear differences. For the removal of $\mathrm{Pb}(\mathrm{II}), \mathrm{Cr}(\mathrm{III})$ and $\mathrm{Cu}(\mathrm{II}), \mathbf{H 2}$ is more sensitive to the $\mathrm{pH}$ values than $\mathbf{H 1}$. On the other hand, the biosorption capacity of $\mathbf{H 1}$ to the rest of metal ions under study is low even if $\mathrm{pH}$ reaches 6.0. In contrast, the bleached and dyed hair (H2) shows a better biosorption capacity compared to $\mathbf{H 1}$ for all the metal ions at $\mathrm{pH} 5.0$ and 6.0 due to the presence of new active sulfonate groups and to the increase of the surface area produced during these treatments. This behavior can be explained since the sulfonate groups created on $\mathbf{H 2}$ surface (after bleaching and dying process) makes it more sensitive to $\mathrm{pH}$ change.

\subsection{Effect of the initial metal concentration}

The effect of the initial metal concentration was evaluated for solutions containing multiple heavy metals, using previously optimized $\mathrm{pH}(\mathrm{pH}=4.0)$ and contact time $(24 \mathrm{~h})$. The initial metal ion concentration increase from $0.5 \times 10^{-3}$ to $0.5 \mathrm{mmol} / \mathrm{L}$. Corresponding results are shown in Figure 2 .

Figure 2 shows that the concentrations of biosorbed metal at the equilibrium increased with the increase 
on the initial concentration of metal ions, which is attributed to an increase of the mass-transfer driving force.

As it can be seen, the maximum biosorption capacity of $\mathbf{H 1}$ and $\mathbf{H} 2$ was reached for some metal ions, including $\mathrm{Mn}(\mathrm{II}), \mathrm{Co}(\mathrm{II}), \mathrm{Ni}(\mathrm{II}), \mathrm{Zn}(\mathrm{II})$ and $\mathrm{Cd}(\mathrm{II})$, for initial concentration above $0.05 \mathrm{mmol} / \mathrm{L}$ for $\mathbf{H 1}$ and $0.2 \mathrm{mmol} / \mathrm{L}$ for $\mathbf{H 2}$. On the contrary, the biosorption capacity at equilibrium of $\mathrm{Pb}(\mathrm{II}), \mathrm{Cr}(\mathrm{III})$ and $\mathrm{Cu}(\mathrm{II})$ for H1 and $\mathbf{H 2}$ continuously increase with the increase of their initial concentration due to the difference of affinity between $\mathrm{Pb}(\mathrm{II}), \mathrm{Cr}(\mathrm{III})$ and $\mathrm{Cu}(\mathrm{II})$ in comparison with the rest of the metals. In this regard, as previously reported, significant amounts of $\mathrm{Pb}$ (II) were removed whereas a less amount of Cd (II) was recovered (Krishnan S.S, Cancilla A. and Jervis R.E, 1988).

\section{(Insert Figure 2 here)}

\subsection{FTIR and SEM characterization}

Two different hair systems (H1 and H2, as indicated previously) were characterized by FTIR. As showed in Figure 3 and Table 1, IR absorption bands at 1040, 1075, 1175, and $1229 \mathrm{~cm}^{-1}$ all correspond to different products of cystine oxidation. The other peaks at $1241,1454,1518$, and $1637 \mathrm{~cm}^{-1}$ are related to chemical groups of the typical amino acid constituents of human hair. It has been seen that there were no significant differences with other human hair reported previously in the literature (Kim and Park, 2013). In addition, the FTIR absorption bands of both human hairs samples before and after the metal biosorption are not substantially different, indicating that the main functional groups on human hair did not change during the metal biosorption process which can be an indication of a possible reuse of such biomaterial. Nevertheless, comparing $\mathbf{H 1}$ and $\mathbf{H 2}$, before and after heavy metal biosorption process, only slightly differences in the profile of the bands were found in the range of 1000 to $1300 \mathrm{~cm}^{-1}$ (as can be seen in Figure $3 \mathrm{~b}$ ). For $\mathbf{H 2}$ sample, the intensity of the peaks at 1041 and $1175 \mathrm{~cm}^{-1}$ of $\mathbf{H 2}$ were higher, as well as the profile became sharper, compared to $\mathbf{H 1}$ sample, due to the greater presence of sulfonate $\left(\mathrm{R}_{-} \mathrm{SO}_{2} \mathrm{O}^{-}\right)$in $\mathbf{H} 2$ sample as a result of the oxidation reactions produced during bleaching and/or dyeing treatments carried out. 


\section{(Insert Figure 3 and Table 1 here)}

Apart from chemical structure, the morphology of a biomass also plays an important role in the biosorption process (López-Mesas et al., 2011). So, SEM micrographs were obtained from H1 and H2, before and after the heavy metal biosorption process (Figure 4). As it can be seen, the surface topography of H1 and H2 is slightly different (Figure 4a and 4c, respectively). The bleached and dyed hair H2, showed more "jagged" or "chipped" appearance, probably due to those treatments (corresponding to the bleaching and dyeing processes). The rougher surface of $\mathbf{H} \mathbf{2}$ results in an increase of the surface area, which acts by promoting the biosorption of metals, and supports the higher biosorption capacity obtained for $\mathbf{H} \mathbf{2}$ in front of H1 sample (Figure 2). Furthermore, the biosorption of metals onto the human hair did not affect significantly the morphology of $\mathbf{H 1}$ and $\mathbf{H 2}$ as it can be seen by comparison of Figures 4a and 4b (for H1), and $4 \mathrm{c}$ and $4 \mathrm{~d}$ (for $\mathbf{H 2}$ ).

\section{(Insert Figure 4 here)}

FTIR and SEM characterization results showed that $\mathbf{H 2}$ sample has a bigger surface area as well as more quantity of active sulfonate groups. Consequently, biosorption capacity of $\mathbf{H} \mathbf{2}$ is expected to be higher than for $\mathbf{H 1}$ as it was obtained from the kinetic results. The fact that no morphological differences are found before and after the biosorption process, pointed up that these samples could be reusable, so it can be a practical biosorbent system for further real applications.

\subsection{Kinetic studies}

Kinetic studies were conducted for both different human hair samples (H1 and H2) to determine the maximum uptake of each metal ions from the initial multiple heavy metal aqueous solution. Figure 5 shows the percentage of biosorption of the eight metal ions (Cr(III), Mn(II), Co(II), Ni(II), Cu(II), $\mathrm{Zn}(\mathrm{II}), \mathrm{Cd}(\mathrm{II})$ and $\mathrm{Pb}(\mathrm{II}))$ onto $\mathbf{H 1}$ and $\mathbf{H 2}$ at different contact times $(5,10,20,30$, and 45 minutes, and 1, 2, 3, 4, 6, 12, 24, 48 and 72 hours). 


\section{(Insert Figure 5 here)}

From the results shown in Figure 5, it is clear that the two different hairs (H1 and H2) show different biosorption capacities to the different heavy metal ions under study. In general, $\mathbf{H} 2$ reaches the maximum metal uptake in less than $1 \mathrm{~h}$ showing better biosorption efficacy than $\mathbf{H 1}$. For H1, even after $48 \mathrm{~h}$ of contact between the hair and the heavy metal ion solutions, the system did not reach a maximum uptake value and an equilibrium state for most of the heavy metals studied. For $\mathbf{H 1}$, only $\mathrm{Cu}(\mathrm{II}), \mathrm{Cr}(\mathrm{III})$ and $\mathrm{Pb}(\mathrm{II})$ have high biosorption percentages over this time, around 90\%. Percentages of biosorption of $\mathrm{Cr}(\mathrm{III}), \mathrm{Cu}(\mathrm{II})$ and $\mathrm{Pb}$ (II) by using $\mathbf{H 2}$ sample reached over $95 \%$ in less than $30 \mathrm{~min}$. The higher sorption of $\mathbf{H 2}$ sample is due to the bigger surface area and more abundant accessible functional groups formed during bleaching and dyeing processes as it was demonstrated by SEM and FTIR results. Both $\mathbf{H 1}$ and $\mathbf{H 2}$ show better biosorption capacity to $\mathrm{Cr}(\mathrm{III}), \mathrm{Cu}(\mathrm{II})$ and $\mathrm{Pb}$ (II) compared with the rest of metal ions in aqueous solution which have an uptake capacity that increases as follow: $\mathrm{Cd}(\mathrm{II})>\mathrm{Zn}(\mathrm{II})>\mathrm{Ni}(\mathrm{II})>\mathrm{Co}(\mathrm{II})>\mathrm{Mn}(\mathrm{II})$, and getting always higher biosorption percentages when using $\mathbf{H 2}$ as biosorbent. Given that the biosorption of the $\mathrm{Cd}(\mathrm{II}), \mathrm{Zn}(\mathrm{II})$, $\mathrm{Ni}(\mathrm{II}), \mathrm{Co}(\mathrm{II})$ and $\mathrm{Mn}(\mathrm{II})$ onto $\mathrm{H1}$ was very low (the percentage of biosorption lower than $40 \%$ even for longer contact time i.e. $70 \mathrm{~h}$ ), the kinetic analysis was not considered for the sorption of these metals onto H1 sample. These results are in agreement with the ones reported by Tan T.C. et al. (Tan T.C., Chia C.K. and Teo C.K., 1985) and Krishman S.S. et al. (Krishnan S.S, Cancilla A. and Jervis R.E, 1988) which showed that human hair has a great capacity for recovering $\mathrm{Cr}(\mathrm{III}), \mathrm{Cu}(\mathrm{II})$ and $\mathrm{Pb}(\mathrm{II})$ and a more limited sorption capacity for $\mathrm{Cd}(\mathrm{II})$ and $\mathrm{Ni}(\mathrm{II})$. In addition, Tan T.C. et al. also reported a profound effect of the presence of other metal ion on the sorption of the metal in a mixed metal ion system. Nevertheless, the percentage of biosorption, even for short contact times, was significative for all metal ions onto $\mathbf{H 2}$ sample (Cd(II) (90\% \pm 0.06$), \mathrm{Zn}(\mathrm{II})(92 \% \pm 0.23), \mathrm{Ni}(\mathrm{II})(75 \% \pm 0.26), \mathrm{Co}(\mathrm{II})(63 \% \pm 0.14)$ and $\mathrm{Mn}(\mathrm{II})(49 \% \pm 0.19))$, and for this reason all the set of eight heavy metals were considered for modeling the kinetics of biosorption onto H2. In brief, it is worth to note that $\mathbf{H 2}$ sample is a better biosorbent relative to $\mathbf{H 1}$. 


\subsection{Biosorption kinetics modeling}

In order to investigate the kinetics of biosorption of heavy metals onto the hair, the pseudo-first (Ho and McKay, 1998) and pseudo-second (Ho and McKay, 1999) orders kinetic models and the Weber-Morris intraparticle diffusion model (Weber and Morris, 1963) are tested.

\subsubsection{Pseudo-first order rate equation}

The linear form of the pseudo-first order rate equation, also called Langergren equation is given by the equation 4:

$\log \left(q_{e}-q_{t}\right)=\log q_{e}-\frac{k_{1}}{2.303} t$

where $q_{e}$ and $q_{t}$ are the concentration of biosorbed metal ion per unit of mass biosorbent (in mmol/g) at the equilibrium and at time $t$ (min), respectively, and $k_{1}$ is the rate constant of the equation (in $\mathrm{min}^{-1}$ ).

The plots of $\log \left(q_{e}-q_{t}\right)$ vs. $t$ for the pseudo-first order model results in the rate rate constants $\left(k_{l}\right)$, the $R^{2}$ and the $q_{e}$ values given in Table 2 .

\section{(Insert Table 2 here)}

Generally, the pseudo-first order equation does not fit well for the whole range of contact time, so it is applicable over the initial time of sorption process. So, the initial rapid step, where biosorption was fast, has been chosen and the experimental data of this step were fitted by the pseudo-first order model. For H1, the range time was less than $24 \mathrm{~h}$ when determining $\mathrm{Cu}(\mathrm{II}), \mathrm{Cr}(\mathrm{III})$ and $\mathrm{Pb}(\mathrm{II})$. For $\mathbf{H 2}$, the range time was less than 30 min for $\mathrm{Cu}(\mathrm{II}), \mathrm{Cr}(\mathrm{III})$ and $\mathrm{Pb}(\mathrm{II})$, and less than $1 \mathrm{~h}$ for the rest of the metals (Cd(II), $\mathrm{Ni}(\mathrm{II}), \mathrm{Zn}(\mathrm{II})$, $\mathrm{Co}(\mathrm{II})$ and $\mathrm{Mn}(\mathrm{II})$ ). For both hair systems, correlation coefficients are found to be above 0.87 , but the calculated $q_{e}$ is not equal to experimental $q_{e}$, suggesting the insufficiency of the pseudo-first order model to fit the experimental data for the initial period of time. In order to address this issue the pseudo-second order model was applied to the analysis of the kinetic experimental results.

\subsubsection{Pseudo-second order rate equation}

The same experimental data were also adjusted to the pseudo-second order kinetic model which is 
given in the following form (equation 5):

$\frac{t}{q_{t}}=\frac{1}{k_{2} q_{e}^{2}}+\frac{t}{q_{e}}$

where $k_{2}$ is the rate constant of the second-order equation (in $\mathrm{mmol} / \mathrm{g} \mathrm{min}$ ), $q_{e}$ and $q_{t}$ are the concentration of biosorbed metal ion per unit of mass biosorbent (in $\mathrm{mmol} / \mathrm{g}$ ) at the equilibrium and at time $t$ (min), respectively.

The plots of $t / q_{t}$ vs. $t$ for the pseudo-second order model results in the corresponding rate constants $\left(k_{2}\right)$, the $R^{2}$ and the $q_{e}$ values given in Table 2 . This model is more likely to predict kinetic behavior of biosorption of heavy metal ions into hair for the whole range of contact time studied, indicating that chemical sorption due to the formation of chemical bonds between the metal and sorbent in a monolayer onto the surface is the rate-controlling step (Ho and McKay, 1999).

As can be seen from the Table 2, pseudo-second order kinetic model provides the better prediction of the biosorption kinetics for whole range of contact time studied compared with pseudo-first order kinetic model. It was corroborated by the extremely high correlation coefficients $R^{2}$ (Table 2) and the good regression curves showed in Figure 6 (continuous curves), for $\mathbf{H 1}$ and $\mathbf{H 2}$, where theoretical biosorption capacity $\left(q_{t}\right)$ data were calculated by the pseudo-second order model and compared with the experimental data. Moreover, the relationship between the measured and the predicted data was better for $\mathbf{H} \mathbf{2}$ compared to H1. So, it seems that chemical sorption is the rate-controlling step in this biosorbate-biosorbent pair system, as the pseudo-second order model provides the best correlation of the experimental data.

\section{(Insert Figure 6 here)}

\subsubsection{Weber-Morris intraparticle diffusion model}

The intraparticle diffusion model proposed by Weber and Morris in 1962 has been widely applied in the determination of intraparticle diffusion rate constant, $k_{3}$, and the boundary resistance, $k_{d}$ (Weber and Morris, 1963). This model is expressed as the following equation 6 : 
$q_{t}=k_{3} t^{1 / 2}+k_{d}$

where $k_{3}$ is the intraparticle diffusion rate constant $\left(\mathrm{mmol} /\left(\mathrm{g} \mathrm{min}{ }^{1 / 2}\right)\right)$ and $k_{d}$ is the intercept that gives idea about the thickness of the boundary layer, and $q_{t}$ is the concentration of biosorbed metal ion per unit of mass biosorbent (in $\mathrm{mmol} / \mathrm{g}$ ) at time $t(\mathrm{~min})$.

According to Weber and Morris, if the rate-limiting step is intraparticle diffusion, a plot of solute sorbed $\left(q_{t}\right)$ against the square root of the contact time $(t)$ should yield a straight line passing through the origin. In this case, the plot can be divided into multi-linearity correlations (Figure 7), which indicates that three steps occur during the whole biosorption process (Ofomaja, 2010) (Wu, Tseng and Juang 2009) and therefore many steps influence the sorption process. The first linear portion can be attributed to the transport of metal species from the solution to the external surface of the biosorbent through film diffusion, especially to the diffusion of the metal species on the boundary layer. The second linear portion describes the gradual biosorption where the intraparticle diffusion is rate-limiting. The third stage was attributed to the final equilibrium where the intraparticle diffusion starts to slow down due to extremely low biosorbate concentration left in solution. Moreover, the deviation of straight line from the origin indicated that the pore diffusion is not the sole rate-controlling step. Consequently, both the film diffusion and intraparticle diffusion were simultaneously operating during the biosorption process.

\section{(Insert Figure 7 here)}

\subsection{Sorption isotherm modeling}

Freundlich and Langmuir isotherm models (Febrianto et al., 2009) (Liu et al., 2004) were selected to fit the experimental data of biosorption of $\mathrm{Pb}$ (II). The linear forms of the Freundlich and Langmuir isotherms are presented by the following equations, (equation 7) and (equation 8), respectively:

$\log q_{e}=\log k_{F}+\frac{1}{n} \log C_{e}$ 
$\frac{C_{e}}{q_{e}}=\frac{b}{K_{L}} C_{e}+\frac{1}{K_{L}}$

where $C_{e}$ is the equilibrium concentration of the metal ion in the residual solution (in mol/L), $q_{e}$ is the equilibrium concentration of the sorbed per unit of mass of sorbent (in mol/g), $k_{F}$ and $n$ are Freundlich constants, and $K_{L}=Q_{0} b$, where $Q_{0}$ and $b$ are the Langmuir constants. $\mathrm{Q}_{0}$ and b correspond to the saturation concentration of the sorbed metal ion per unit of mass of sorbent (in $\mathrm{mol} / \mathrm{g}$ ) and the ratio of sorption/desorption rates (in L/mol), respectively.

For both models and following equations (7) and (8), $\log q_{e}$ versus $\log C_{e}$ and $C_{e} / q_{e}$ versus $C_{e}$ are calculated and compared with the experimental data, respectively. Also, all the constants and correlation coefficients obtained for each model are summarized in Table 3.

\section{(Insert Table 3 here)}

From the correlation coefficient values, it was observed that the Langmuir isotherm $\left(R^{2}>0.99\right)$ fitted the data better than the Freundlich isotherm showing that the biosorption process rely on a specific sites sorption mechanism where adsorbate molecules occupy specific sites on the biosorbent. Taking on board the Langmuir equation, the saturated biosorption capacity of $\mathbf{H 1}$ and $\mathbf{H 2}$ at $295 \mathrm{~K}$ for $\mathrm{Pb}(\mathrm{II})$ were calculated: $1.70 \times 10^{-5}$ and $23.2 \times 10^{-5} \mathrm{~mol} / \mathrm{g}$, respectively.

In addition, from the estimated Langmuir sorption/desorption constant, the standard Gibb's free energy $\left(\Delta G^{0}\right)$ of the biosorption process can be evaluated by using the following equation (9):

$\Delta G^{0}=-R T \ln b$

where $b$ is the Langmuir equilibrium constant shown in equation (8), $R$ is the universal gas constant $(8.314$ $\mathrm{J} / \mathrm{mol} \mathrm{K}$ ) and $T$ is the absolute temperature $(\mathrm{K})$. The standard Gibb's free energy $\left(\Delta G^{0}\right)$ values of $\mathbf{H 1}$ and $\mathbf{H} 2$ are shown in Table 3. The negative $\Delta G^{0}$ values indicated that the biosorption of metals into human hair is thermodynamically feasible and of spontaneous nature.

\section{Conclusions}


The biosorption of $\mathrm{Cr}(\mathrm{III}), \mathrm{Mn}(\mathrm{II}), \mathrm{Co}(\mathrm{II}), \mathrm{Ni}(\mathrm{II}), \mathrm{Cu}(\mathrm{II}), \mathrm{Zn}(\mathrm{II}), \mathrm{Cd}(\mathrm{II})$ and $\mathrm{Pb}(\mathrm{II})$ from their multiple aqueous solutions by two different hair systems were investigated. The bleached and dyed hair (H2) showed better biosorption capacity than $\mathbf{H 1}$ (untreated one). The biosorption capacities of the heavy metal ions followed the order $\mathrm{Cu}(\mathrm{II})>\mathrm{Pb}(\mathrm{II})>\mathrm{Cr}(\mathrm{III})>\mathrm{Zn}(\mathrm{II})>\mathrm{Cd}(\mathrm{II})>\mathrm{Ni}(\mathrm{II})>\mathrm{Co}(\mathrm{II})>\mathrm{Mn}(\mathrm{II})$ for $\mathbf{H} 2$, and $\mathrm{Cu}(\mathrm{II})>$ $\mathrm{Cr}(\mathrm{III})>\mathrm{Pb}(\mathrm{II})$ for $\mathbf{H 1}$, being not significant the biosorption of the rest of the heavy metal ions for H1. The operating parameters, such as the contact time, the $\mathrm{pH}$ of the aqueous solution and the initial metal concentration strongly affect the efficacy of removing the selected heavy metal ions under study. $\mathbf{H} 2$ shows faster biosorption rate than H1. The optimum $\mathrm{pH}$ value is 4.0. For the multiple heavy metal solution, the maximum removal of $\mathrm{Cu}(\mathrm{II}), \mathrm{Cr}(\mathrm{III})$ and $\mathrm{Pb}(\mathrm{II})$ efficiencies are found to be higher than $90 \%$ for $\mathbf{H 1}$ and higher than $95 \%$ for $\mathbf{H 2}$. Kinetic modeling of the equilibrium data shows that the biosorption of heavy metal ions onto human hair follows well the pseudo-second order kinetic and the Weber-Morris intraparticle diffusion models, which means that both chemisorption and intraparticle diffusion are the rate-controlling steps. Biosorption at equilibrium was better correlated with Langmuir isotherm model compared to Freundlich model. The calculated standard Gibb's free energy $\left(\Delta G^{0}\right)$ indicated the feasibility and spontaneous nature of the biosorption process. The better biosorption capacity of $\mathbf{H 2}$ was attributed to the more abundant active functional groups (especially sulfonate ones) formed during bleaching and dyeing treatments and the bigger surface area relative to H1. So, the human hair shows satisfactory biosorption capacity, which can be enhanced with the common bleaching and dyeing treatments, and can be considered as a potential biosorbent for the removal of heavy metal ions.

\section{Acknowledgements}

This work was financial supported by the CTM2012-30970 and CTM2015-65414-C2-1-R Spanish research projects, and by the European project ORQUE-SUDOE SOE3-P2-F591. Helan Zhang thanks to the China Sholarship Council for the grant [2001]3005. The authors are grateful to the UAB Microscopy Service for the SEM analysis and the Service of Analytical Chemistry for the analysis of FTIR. Also, authors are 
grateful to M. Resina who helped performing the analysis of heavy metals by ICP-MS.

\section{Conflict of Interest}

There are no conflicts of interest associated with this publication.

\section{References}

Ahalya N, Ramachandra T, Kanamadi R, 2003. Biosorption of heavy metals. Research Journal of Chemical and Environment, 7(4): 71-79.

Amer, H., El-Gendy, A., \& El-Haggar, S. (2017). Removal of lead (II) from aqueous solutions using rice straw. Water Science and Technology, 76(5), 1011-1021.

Amuda O.S., Giwa, A.A., Bello, I.A. (2007). Removal of heavy metal from industrial wastewater using modified activated coconut shell carbon. Biochemical Engineering Journal, 36, 174-181.

Beni, A. A., \& Esmaeili, A. (2020). Biosorption, an efficient method for removing heavy metals from industrial effluents: A review. Environmental Technology and Innovation, 17.

Butt, W.A., Mir, B.A. \& Jha, J.N. (2016). Strength Behavior of Clayey Soil Reinforced with Human Hair as a Natural Fibre. Geotechnical and Geological Engineering, 34, 411-417.Carolin, C. F., Kumar, P. S., Saravanan, A., Joshiba, G. J., Naushad, M. (2017). Efficient techniques for the removal of toxic heavy metals from aquatic environment: A review. Journal of Environmental Chemical Engineering, 5(3), 2782-2799.

Castro, L., Blázquez, M. L., González, F., Muñoz, J. A., \& Ballester, A. (2017). Biosorption of zn(II) from industrial effluents using sugar beet pulp and F. vesiculosus: From laboratory tests to a pilot approach. Science of the Total Environment, 598, 856-866.

Davis T. A., Volesky B., Mucci A. (2003). A review of the biochemistry of heavy metal biosorption by brown algae. Water Research, 37(18): 4311-4330.

Febrianto J., Kosasih A. N., Sunarso J., Ju Y-H., Indraswati N., Ismadji S. (2009). Equilibrium and kinetic studies in adsorption of heavy metals using biosorbent: A summary of recent studies. Journal of Hazardous Materials, 162(2-3), 616-645.

Gorgievski, M., Božić, D., Stanković, V., Štrbac, N., \& Šerbula, S. (2013). Kinetics, equilibrium and 
mechanism of $\mathrm{Cu}^{2+}, \mathrm{Ni}^{2+}$ and $\mathrm{Zn}^{2+}$ ions biosorption using wheat straw. Ecological Engineering, 58, 113-122. Gupta A. (2014). Human hair "waste" and its utilization: gaps and possibilities, Journal of Waste Management 1-17.

Ho Y. S., McKay G. (1998). A Comparison of Chemisorption Kinetic Models Applied to Pollutant Removal on Various Sorbents. Process Safety and Environmental Protection, 76(4): 332-340.

Ho Y. S., McKay G. (1999). Pseudo-second order model for sorption processes. Process Biochemistry, 34(5): 451-465.

Kaakani, M., Mortula, M. M., \& Abouleish, M. Y. (2017). Palm tree leaves usage for biosorption and recovery of heavy metals from wastewater. Desalination and Water Treatment, 80, 184-192.

Kar P., Misra M. (2004). Use of keratin fiber for separation of heavy metals from water. Journal of Chemical Technology and Biotechnology, 79(11): 1313-1319.Kim K. S., Park H. K. (2013). Analysis of aging effects on chemical property of human hair by Fourier transform infrared spectroscopy. Skin Research and Technology, 19(1): 325-331.

Krishnan S.S., Cancilla A. and Jervis R. E. (1988). Waste water treatment for heavy metal toxins using plant and hair as adsorbents. Science of the Total Environment, 68(1), 267-273.Lazaridis N K, Kyzas G Z, Vassiliou A A, Bikiaris D N. (2007). Chitosan derivatives as biosorbents for basic dyes. Langmuir, 23(14): 7634-7643.

Lee, H., Noh, K., Lee, S.C., Kwon I.K., Han D. W., Lee I. S., Hwan Y.S. (2014). Human hair keratin and its-based biomaterials for biomedical applications. Tissue Engineering and Regenerative Medicine, 11, $255-265$.

Liu H. L., Chen B. Y., Lan Y. W., Cheng Y. C. (2004). Biosorption of Zn(II) and Cu(II) by the indigenous Thiobacillus thiooxidans. Chemical Engineering Journal, 97(2-3), 195-201.

Liu R., Ma W., Jia C.Y., Wang L., Li H. Y. (2007). Effect of pH on biosorption of boron onto cotton cellulose. Desalination, 207(1-3): 257-267.

López-Mesas M., Navarrete E. R., Carrillo F., Palet C. (2011). Bioseparation of Pb(II) and Cd(II) from aqueous solution using cork waste biomass. Modeling and optimization of the parameters of the biosorption step. Chemical Engineering Journal, 174(1): 9-17. 
Low K. S., Lee C. K., Liew S. C. (2000). Sorption of cadmium and lead from aqueous solutions by spent grain. Process Biochemistry, 36(1-2): 59-64.

Ofomaja A. E. (2010). Intraparticle diffusion process for lead(II) biosorption onto mansonia wood sawdust. Bioresource Technology, 101(15): 5868-5876.

Olgun A., Atar N. (2012). Equilibrium, thermodynamic and kinetic studies for the adsorption of lead (II) and nickel (II) onto clay mixture containing boron impurity. Journal of Industrial and Engineering Chemistry, 18(5): 1751-1757.

Patnaik, B. B., Howrelia, J. H., \& Selvanayagam, M. (2004). Heavy metal toxicity and bio-accumulation - A critical appraisal. Indian Journal of Environmental Protection, 24(10), 757-761.

Qin, H., Hu, T., Zhai, Y., Lu, N., \& Aliyeva, J. (2020). The improved methods of heavy metals removal by biosorbents: A review. Environmental Pollution, 258.

Saha, S., Zubair, M., Khosa, M. A., Song, S., \& Ullah, A. (2019). Keratin and chitosan biosorbents for wastewater treatment: A review. Journal of Polymers and the Environment, 27(7), 1389-1403.

Sas, O. G., Sánchez, P. B., González, B., \& Domínguez, Á. (2020). Removal of phenolic pollutants from wastewater streams using ionic liquids. Separation and Purification Technology, 236.

Seki, H., Yu, K., Maruyama, H., \& Suzuki, A. (2006). Biosorption of heavy metals onto sphagnum peat moss. Kagaku Kogaku Ronbunshu, 32(5), 409-413.

Shim, Y.S., Kim Y.K., Kong S.H., Rhee S.W., Lee W.K. (2003). The adsorption characteristics of heavy metals by various particle sizes of MSWI bottom ash. Waste Management, 23 (9), 851-857.

Tan T.C., Chia C.K. and Teo C.K. (1985). Uptake of metal ions by chemically treated human hair. Water Research, 19 (2), 157-162.

Tran, H. N., Nguyen, H. C., Woo, S. H., Nguyen, T. V., Vigneswaran, S., Hosseini-Bandegharaei, A., Chao, H., Rinklebe, J., Kumar Sarmah, A., Ivanets, A., Dotto, G.L., Bui, T.T., Juang, R.S., Chao, H.P. (2019). Removal of various contaminants from water by renewable lignocellulose-derived biosorbents: A comprehensive and critical review. Critical Reviews in Environmental Science and Technology, 49(23), 2155-2219.

Ukotije-Ikwut P.R., Idogun A.K., Iriakuma C.T., Aseminaso A., Obomanu T. (2016). A Novel Method for 
Adsorption using Human Hair as a Natural Oil Spill Sorbent. International Journal of Scientific \& Engineering Research, 7(8), 1754-1764.

Wang, Q., Hao, D., Li, F., Guan, X., \& Chen, P. (2020). Development of a new framework to identify pathways from socioeconomic development to environmental pollution. Journal of Cleaner Production, 253. Weber W. J., Morris J. C. (1963). Kinetics of Adsorption of Carbon from Solution. Journal of the Sanitary Engineering Division, American Society of Civil Engineering, , 89(1): 31-60.

Wu F.C., Tseng R. L., Juang R. S. (2009). Initial behavior of intraparticle diffusion model used in the description of adsorption kinetics. Chemical Engineering Journal, 153(1-3): 1-8.

Zhang, H., Carrillo, F., López-Mesas, M., Palet, C. (2019). Valorization of keratin biofibers for removing heavy metals from aqueous solutions. Textile Research Journal, 89(7), 1153-1165.

Zhao J. J., Shen X. J., Domene X., Alcañiz J.M., Liao X., Palet C. (2019). Comparison of biochars derived from different types of feedstock and their potential for heavy metal removal in multiple-metal solutions. Scientific Reports, 9(1):9869.

Zheljazkov V. D., Silva J. L., Patel M., Stojanovic J., Lu Y. Kim T. Horgan T. (2008). Human Hair as a Nutrient Source for Horticultural Crops. HortTechnology, 18(4), 592-596. 